\title{
The Association of Alcohol and Drug Use with Persistence of Violent Offending in Young Adulthood
}

\author{
Helene R. White ${ }^{1}$ • Jennifer Buckman ${ }^{1}$. \\ Dustin Pardini ${ }^{2} \cdot$ Rolf Loeber ${ }^{2}$
}

Received: 19 June 2015 / Revised: 19 August 2015 / Accepted: 21 August 2015 /

Published online: 3 September 2015

(C) Springer International Publishing AG 2015

\begin{abstract}
Purpose This study expanded upon an earlier study, which examined the associations between heavy drinking and persistence of serious violent offending through emerging adulthood (approximate age 25), by examining associations between alcohol, marijuana, and other drug use and disorders and persistence of serious violent offending through young adulthood (approximate age 36).

Methods We used official records and self-reported longitudinal data from Black and White men from early adolescence through young adulthood $(n=391)$. Men were divided into four violence groups: non-violent, desisters, persisters, and very lateonsetters. Multinomial logistic regression analyses controlling for race and incarceration were used to compare these groups in terms of substance use in young adulthood and changes in use from emerging to young adulthood.

Results Most previous serious violent offenders did not re-offend in young adulthood. Whereas alcohol use did not differ across groups, persisters and desisters, compared to non-violent men, were more likely to use hard drugs, deal drugs, have a lifetime substance use disorder diagnosis, and show larger decreases in alcohol and marijuana frequency from emerging to young adulthood. None of these measures differed between persisters and desisters except that persisters reported larger decreases in alcohol and marijuana use frequency.

Conclusions The findings demonstrated reductions in serious violent offending during young adulthood and suggested that after adolescence, illicit drug use, compared to alcohol use, may play a more important role in initiation and maintenance of serious
\end{abstract}

Helene R. White

hewhite@rutgers.edu

1 Center of Alcohol Studies, Rutgers, The State University of New Jersey, 607 Allison Road, Piscataway, NJ 08904, USA

2 Department of Psychiatry, University of Pittsburgh Medical Center, Pittsburgh, PA, USA 
violent offending. Future research that examines the interrelations of drug use, drug culture, and violence is warranted.

Keywords Violence $\cdot$ Substance use $\cdot$ Desistance Persistence $\cdot$ Alcohol Marijuana Dealing

\section{Introduction}

A strong developmental relationship between substance use and criminal offending, including both violent and property offenses, has been observed across numerous studies [52]. There has been much debate in the criminology literature, however, regarding the generality versus specificity of deviant behavior. Some researchers have advocated a general deviance (or behavior problem syndrome) construct consisting of all types of criminal offending and all types of substance use as well as other problem behaviors (e.g., [19, 23]). In contrast, others have advocated a more differentiated approach, suggesting that there are both common and unique predictors of criminal offending and substance use, e.g., [30, 43, 55]. Although Le Blanc and Loeber [28] agreed that both substance use and criminal offending are forms of deviant behavior, they acknowledged that this general pattern can be subdivided into different types of deviance. By studying substance use and crime as two distinct forms of deviance, it allows researchers to investigate how each influences the other [53]. Therefore, in this study, we treat substance use and criminal offending as distinct forms of deviance.

While many studies have shown how alcohol and drug use influence the occurrence of offending, developmental criminologists are also interested in how alcohol and drug use influence desistance from criminal offending [28, 53]. Due to age-normative changes in substance use and offending, these two types of deviance peak at different stages in the life cycle and desistance for most individuals occurs earlier for offending than for substance use. Desistance from criminal offending often begins in late adolescence [8, 32], a time when substance use is generally escalating [2]. For the most part, youth do not mature out of heavy drinking and illicit drug use until they take on adult roles, such as marriage and career [26].

Nevertheless, studies have shown that reductions in substance use in young adulthood may play a key role in reductions in offending $[25,50]$. Furthermore, chronic use of psychoactive substances can impede desistance from offending (e.g., [6, 13, 14, 22, 27, 39, 41]). Consistent with Moffitt's [37] snares hypothesis, Hussong et al. ([22], p. 1043) proposed that substance abuse may slow down desistance by entrenching individuals in antisocial patterns of behavior, increasing the occurrence of snares (e.g., incarceration), and reducing the accumulation of protective factors (e.g., good marriages) (see also [6, 27, 46]).

Most studies on desistance have focused on general offending using either selfreport or official records. Although Laub and Sampson [27] found that desistance processes were quite similar across different types of offenses, violent offending may be related to substance use in distinct ways from other types of offending [18]. For example, the pharmacological effects of heavy drinking may cause acute cognitive impairments, which facilitate the likelihood of violent behavior [12, 17]. There has been less support, however, for the pharmacological effects of drugs on violence (see 
$[36,52]$ for reviews). In addition, illicit drug use may push individuals into drug markets where violence is frequent and normative [7, 52], which has been labeled as systemic violence [18]. White [53] broadened the concept of systemic violence beyond drug market influences to include additional socioenvironmental/contextual influences, such as being involved with drug-using peers who condone and reinforce violence, living in neighborhoods with high levels of drug use and violence, and frequenting certain drinking establishments with characteristics that increase the likelihood of violent behavior.

Few studies have examined the associations between substance use and desistance/persistence of violent offending specifically. In a national sample of Swedes, Falk et al. [13] found that substance use disorders were predictive of persistent violent offending. In another Swedish sample, Nilsson et al. [42] examined recidivism in violent offending among violent perpetrators in forensic psychiatric placement. They found that substance abuse/dependence was no longer significantly related to recidivism once they included age of first conviction and parental substance abuse in the model.

In a study in the United States, White et al. [56] examined the role of heavy drinking on desistance from serious violent offending through the middle 20s. This investigation included Black and White men from the Pittsburgh Youth Study [33] and was based on both self-report and official convictions of serious violent offending. The authors examined how patterns of drinking (quantity and frequency combined) during adolescence (approximate ages 13-17) and emerging adulthood (approximate ages 18-25) were related to persistence of serious violence (i.e., homicide, manslaughter, major assault, robbery, and attempted or completed rape or sexual assault) through emerging adulthood. While it has been argued that it is best to view desistance as a process (dynamic definition) rather than a discrete event (static definition) [5, 11, 24], desistance from serious violent offending could not be measured as a process given its low overall frequency in the sample. Therefore, a conceptual definition was used and desistance was operationalized as refraining from engaging in serious violence for a minimum of 7 years (from ages 18 to 25). A similar time-dependent conceptual definition for desistance from general criminal offending has been used in previous studies (e.g., [4, 48, 51]).

In the White et al. [56] study, five distinct violence groups were identified based on patterns of offending in both adolescence and emerging adulthood: (1) non-violent men, who did not commit a serious violent offense in adolescence or emerging adulthood $(64.9 \%)$, (2) late-onset offenders, who did not commit a serious offense in adolescence but committed at least two violent offenses in emerging adulthood (5.7\%), (3) desisters, who committed at least two serious offenses during adolescence but none in emerging adulthood $(8.5 \%)$, (4) persisters, who committed at least one serious offense in adolescence and at least one during emerging adulthood (11.5\%), and (5) one-time offenders, who committed only one serious violent offense in either adolescence or emerging adulthood but not both $(9.4 \%)$.

White et al. [56] found that heavier alcohol use during adolescence was a risk factor for concurrent serious violent behavior; desisters and persisters reported the greatest amount of drinking during adolescence, compared to the other three groups. However, increased drinking during emerging adulthood was not associated with persistent serious violent offending. White et al. [56] suggested that this finding may be due to 
the fact that heavy drinking during emerging adulthood is normative as non-violent men in the sample substantially increased their drinking in emerging adulthood. In fact, alcohol use by non-violent men surpassed that of persisters and late-onset offenders by age 25. Race was controlled in all analyses and this pattern of results held even when time-varying measures of marijuana and hard drug use and periods of institutionalization (e.g., incarceration and hospitalization) were also controlled.

Overall, the results from White et al. [56] demonstrated the importance of examining the influence of alcohol use on desistance and persistence of violent offending at different developmental periods. That is, heavy drinking during adolescence may be an indicator that presages a persistent criminal career [22, 46], whereas heavy drinking during emerging adulthood is more normative [35] and may be unrelated to violence. However, White et al. [56] hypothesized that heavier drinking after emerging adulthood would become less normative (i.e., perhaps indicative of pathological use) and would again be linked to violent offending.

In contrast to drinking, drug use is an illegal activity that tends to be linked to criminal offending across all periods of development [52]. In a study that followed adolescent offenders past mid-adulthood, Schroeder et al. [48] found that drug use, compared to alcohol use, was more strongly related to continued offending. They suggested that drug use may embed individuals into associations with deviant peers and partners, which reinforce continued involvement in crime. Furthermore, drug users may become involved in drug dealing to support their drug use and drug dealing is often linked to violence due to fights over organizational and territorial issues, enforcement of rules, punishments of and efforts to protect buyers and sellers, and transactionrelated crimes (such as thefts or robberies of dealers or buyers, assaults to collect debts, and resolution of disputes over quality or amount) [7, 36].

The current study extends White et al. [56] by following the same sample of men through their middle 30s (approximate age 36) and examining whether marijuana and hard drug use and dependence in young adulthood in addition to alcohol use and dependence are related to persistence of serious violent offending. By following the men for an additional 10 years into young adulthood, the current study includes a developmental period when one expects to see desistance from violence and substance use. In contrast, the White et al. [56] study followed these men only as far as emerging adulthood, when substance use would be expected to peak [2, 27]. We, thus, can test their hypothesis that heavy drinking in young adulthood would again become related to persistence of violence as it had been during adolescence. In addition, we also move beyond examining the role of alcohol use alone in desistance from violent offending by including associations of violent offending with marijuana and hard drug use, substance use disorders, and drug dealing. Finally, with the additional 10-year follow-up, we can determine the reliability of conceptual definitions of desistance and determine whether men who were defined as desisters from serious violence in their middle 20 s remained desisters over the next 10 years.

We expect that there will be changes in the dynamic classification of offenders when data are extended into the middle $30 \mathrm{~s}$, primarily due to more men maturing out of violent offending. We further hypothesize that non-violent men and desisters, compared to persisters, will report lower rates of alcohol use as well as of drug use and dealing in young adulthood and that non-violent men, compared to desisters and persisters, will report lower rates of lifetime substance use disorders. 


\section{Methods}

\section{Participants}

The current study used data from White and Black men in the oldest cohort of the Pittsburgh Youth Study [33]; White et al. [56] used data from White and Black men from both cohorts. Thus far, the oldest cohort has been followed into their middle $30 \mathrm{~s}$, whereas the youngest cohort has been followed only through their late 20 s. By focusing only on the oldest cohort, it allows for an exploration of an additional 10 years beyond the White et al. study, which moves the men into a new developmental stage, that is, from emerging to young adulthood. This cohort included seventh grade boys $(M$ age $=13.4, S D=0.8$; range $=11.7-15.5)$, who were initially recruited from public schools in Pittsburgh in 1987-1988. Boys were screened for their risk for antisocial behavior based on reports from the boys, their primary caretaker, and a teacher. All boys who scored within the upper $30 \%(n=$ 257 ) and an approximately equal number randomly chosen from the remainder $(n=249)$ were selected for follow-up. The racial/ethnic composition of the 506 boys in the follow-up sample was predominately Black $(54.5 \%)$ and White $(41.7 \%)$, with the remainder being other or mixed race/ethnicity. At screening, nearly all were living with their biological mother (94\%), and approximately half of the boys lived in a household with no biological or acting father $(45.3 \%)$. About one half (50.6\%) of the families received financial public assistance (e.g., food stamps, disability). The follow-up sample was not significantly different from the screening sample in terms of race and family composition [33].

Following screening, boys were initially interviewed every 6 months for five biannual assessments and then annually for the next 10 years (until approximate age 26). Approximately 10 years after that (2009-2010), participants were re-interviewed when they averaged 36 years of age $(M=35.8, S D=0.8$; range 33-39). Of the living men (25 men were deceased), $84.8 \%(N=408 ; n=213$ Black, $n=175$ White, $n=20$ other) were located and agreed to participate. Interviewed participants did not differ from those not interviewed on the screening variables of at-risk status, family socioeconomic status, number of biological parents in the home, parent- and teacherreported internalizing and externalizing problems and substance use during adolescence and emerging adulthood [44, 54].

The study was approved by the University of Pittsburgh Institutional Review Board. All participants provided informed consent (assent through age 17 and written after age 17) prior to the administration of the study procedures. Caretakers provided written consent until the participants were age 18. Greater detail on participant selection, sample characteristics, and study methodology can be found in Loeber et al. [33].

\section{Measures}

\section{Substance Use}

At each assessment, participants reported on the number of times that they used alcohol, marijuana, and hard drugs (e.g., cocaine, stimulants, opiates, 
hallucinogens, PCP) during the past year on the Substance Use Scale [9]. Pastyear frequency of binge drinking (defined as drinking at least five drinks in a 2-h period) [40] was also assessed at age 36. Due to the relatively low rate of hard drug use in the sample, it was dichotomized into any hard drug use in the past year at age 36 (coded 1) or no use (coded 0). Changes in frequency of alcohol and marijuana use from emerging adulthood to young adulthood were calculated by subtracting the highest annual frequency of use between ages 18 and 25 from the frequency of use at age 36.

Lifetime substance use disorders were assessed at age 36 by the Diagnostic Interview Schedule [21] based on DSM-IV criteria [1]. Any positive diagnosis for DSM-IV abuse or dependence was coded as a use disorder. Disorders for alcohol, cannabis, and other drugs were assessed separately. The number of lifetime abuse and dependence symptoms for alcohol, cannabis, and other drugs was also assessed but results using these count variables were quite similar to those reported below for the dichotomous diagnoses and thus are not reported herein (available from the first author upon request). Self-report of any drug dealing in the past year at age 36 (which was coded $1=$ yes and $0=$ no) was also assessed using the Self-Reported Delinquency (SRD) Scale [9].

\section{Violent Offending}

Self-report of serious violent offending was obtained from the SRD [9]. Serious violent offenses included: completed or attempted rape or sexual assault, use of force or threats of force to get money or things from others (i.e., robbery), and attacks intended to seriously hurt of kill. At the age 36 interview, participants reported on whether they had engaged in each of these offenses since age 18. If yes, participants were asked their age at last occurrence and frequency in the last year. These measures were combined to create a self-report measure of any serious violent offending in the last 10 years. In addition, official criminal convictions for serious violence were collected from the Pennsylvania (PA) State Police, PA Clerk of Courts, and the Federal Bureau of Investigation. Official records of offending in adulthood were updated through 1 January 2012 for all participants, even those who did not complete the last interview. Serious violence convictions included homicide, voluntary manslaughter, sexual assault, aggravated assault, and robbery. Self-reports and official charges were combined (see "Data Analysis" section below).

\section{Control Variables}

Race was dichotomized (White $=0$, Black $=1$ ). Incarceration at any point in the 10 year period before the young adulthood follow-up ( age 36) was assessed by selfreport and official records. This variable was dichotomized and coded 1 if, at the age 36 interview, the respondent was physically resident in a correctional facility, the respondent reported any arrest since the previous interview leading to incarceration, the respondent reported living in a correctional facility at any time since the previous interview, or official records indicated that the respondent was incarcerated at any time since the previous interview. This variable was included to account for time at risk for substance use [45]. 


\section{Data Analysis}

Individuals were initially categorized into the five emerging adult violence subgroups defined by White et al. [56] (i.e., non-violent youth, late onset offenders, desisters, persisters, and one-time offenders). Serious violent offending between emerging adulthood ( age 25) and young adulthood ( age 36) was then combined with the original classification and men were re-categorized into the four new violence groups (see "Results" section below). All living White and Black men had official criminal record data $(N=461)$ but self-report violence data were missing for Black and White men not interviewed at age $36(N=73)$. Because $67 \%$ of the men who self-reported a serious violent offense in the last 10 years had no official conviction record for a serious violent offense, participants with no official convictions who were missing self-report data were not included in the new young adult violence groups $(N=70)$. Thus, men designated as desisters had at least 10 years without a serious violent offense as assessed by self-report and official records. Conversely, men with a conviction record were included in the new violence groups regardless of whether self-report data were available (three men not interviewed at age 36 had an official conviction for a serious violent offense and are thus included in the young adult violence groups).

Substance use behaviors were then compared between the updated violence groups using multinomial logistic regression analyses with contrast coding. Each of the five continuous (alcohol, marijuana, and hard drug use frequency in past year and changes in alcohol and marijuana use since emerging adulthood) and five dichotomous (use of any hard drug, drug dealing, and alcohol, cannabis, and other drug use disorder diagnoses) predictors were tested independently. Frequency of alcohol use, marijuana use, and binge drinking were log transformed to reduce skew. We controlled for race and for past 10-year incarceration in all regression analyses. For these analyses, the sample is reduced to 387 men who were interviewed at age 36 , had self-report data on substance use at age 36 , and were either Black $(n=212)$ or White $(n=175)$. All analyses were performed in SAS 9.3 [47].

\section{Results}

\section{Consistency of Violence Group Classification}

By combining the groups from emerging adulthood with the information on offending between ages 26 and 36, we identified four new violence groups in young adulthood: (1) non-violent men were those who had committed no serious violent offenses in adolescence, emerging adulthood, and young adulthood (56.3\%); (2) desisters were men who committed one or more serious violent offenses in adolescence and/or emerging adulthood but none in young adulthood (35.0\%); (3) persisters were men who committed one or more serious violent offenses during adolescence and/or emerging adulthood and also at least one in young adulthood (6.1\%); and (4) very late-onset offenders were men who did not commit a serious violent offense in adolescence or emerging adulthood but committed at least one during young adulthood $(2.6 \%)$. 
Table 1 shows the percentage of men in each of the five original emerging adult violence groups who maintained their original group membership and characterizes change in those who did not maintain membership. Most of the non-violent men remained non-violent, although $4.4 \%$ of them violently offended at least once during young adulthood thus becoming a small group of very late-onset offenders $(n=10)$. Among those originally classified as late-onset offenders, most (78.1\%) desisted in the subsequent years. Based on the original conceptualizations of the violence groups, members of this group may be more accurately referred to as time-limited late-onset violent offenders (desisters). About one fifth (21.9\%) of the late-onset group committed another serious violent offense in young adulthood; these individuals were thus classified as persisters. Only a few $(10.0 \%)$ of the men who were originally defined as desisters at age 25 committed at least one additional serious violent offense between ages 26 and 36, suggesting they would more accurately be classified as violence persisters once the window of offending increased. Conversely, most (80.9\%) of those defined as persisters at age 25 did not violently offend again through age 36 , suggesting that they would be better classified as late desisters from violent offending. Finally, $5.6 \%$ of the one-time violent offenders identified in emerging adulthood committed at least one other serious violence offense between ages 26 and 36, and thus would be better classified as persisters based on the extended follow-up, whereas $94.4 \%$ did not commit another offense making them desisters.

\section{Violence Groups Differences in Substance Use}

For descriptive purposes, Table 2 shows the mean frequency of alcohol use, binge drinking, and marijuana use at age 36 and changes in alcohol and marijuana use from emerging to young adulthood for the young adult violence groups (note that we show unlogged means for ease of interpretation). Table 2 also shows the percentage of each group who used hard drugs, dealt drugs, and was diagnosed with a lifetime substance use disorder.

We conducted multinominal logistic regression analyses, first with the non-violent men as the reference group and then with the persisters as the reference group, to see whether the means and percentages shown in Table 2 differed significantly across the violence groups. The very late-onset group was excluded from the multinomial logistic regression analyses because the sample size was too small $(n=10)$. All analyses controlled for race and incarceration. There were significant race differences in violence

Table 1 Percent of original violence group members who maintained or changed group membership during young adulthood $(n=391)$

\begin{tabular}{llll}
\hline Original group & Original group $N$ & $\begin{array}{l}\text { Percent maintaining group } \\
\text { membership }\end{array}$ & $\begin{array}{l}\text { Description of those } \\
\text { who changed status }\end{array}$ \\
\hline Non-violent & 230 & $95.6 \%$ & $4.4 \%$ (very late-onset) \\
Late onset & 32 & - & $78.1 \%$ (desisters), $21.9 \%$ (persisters) \\
Desisters & 30 & $90.0 \%$ & $10.0 \%$ (persisters) \\
Persisters & 63 & $19.1 \%$ & $80.9 \%$ (desisters) \\
One-time & 36 & - & $94.4 \%$ (desisters), $5.6 \%$ (persisters) \\
\hline
\end{tabular}


Table 2 Substance use characteristics of the violence groups in young adulthood (approximate age 36)

\begin{tabular}{|c|c|c|c|c|}
\hline & $\begin{array}{l}\text { Non-violent men } \\
(n=219)\end{array}$ & $\begin{array}{l}\text { Desisters } \\
(n=137)\end{array}$ & $\begin{array}{l}\text { Persisters } \\
(n=21)\end{array}$ & $\begin{array}{l}\text { Very late onset } \\
(n=10)\end{array}$ \\
\hline \multicolumn{5}{|c|}{ Continuous variables (mean \pm standard deviation) } \\
\hline Alcohol use frequency ${ }^{\mathrm{a}, \mathrm{d}}$ & $67.7 \pm 89.1$ & $56.6 \pm 73.0$ & $57.9 \pm 109.4$ & $44.5 \pm 62.7$ \\
\hline Binge drinking frequency ${ }^{\mathrm{a}, \mathrm{d}}$ & $9.6 \pm 42.3$ & $8.5 \pm 29.3$ & $22.2 \pm 81.5$ & $11.0 \pm 31.3$ \\
\hline Marijuana use frequency ${ }^{\mathrm{a}, \mathrm{d}}$ & $37.1 \pm 103.1$ & $69.2 \pm 125.0$ & $49.7 \pm 115.0$ & $12.4 \pm 31.7$ \\
\hline Change in alcohol use $\mathrm{b}^{\mathrm{b}, \mathrm{e}}$ & $-82.1 \pm 109.2$ & $-132.1 \pm 128.3$ & $-215.6 \pm 144.7$ & $-134.5 \pm 141.4$ \\
\hline Change in marijuana use $\mathrm{e}^{\mathrm{b}, \mathrm{f}}$ & $-36.5 \pm 117.2$ & $-100.7 \pm 152.2$ & $-240.7 \pm 144.7$ & $-147.0 \pm 169.2$ \\
\hline \multicolumn{5}{|l|}{ Categorical variables ( $\%$ positive) } \\
\hline Any hard drug use $\mathrm{a}^{\mathrm{a}}$ & 4.6 & 15.3 & 23.8 & 0 \\
\hline Drug dealing $^{\mathrm{a}}$ & 2.3 & 10.2 & 23.8 & 0 \\
\hline Alcohol use disorder ${ }^{c}$ & 26.3 & 41.6 & 57.1 & 10.0 \\
\hline Cannabis use disorder ${ }^{\mathrm{c}}$ & 4.6 & 11.7 & 23.8 & 0 \\
\hline Hard drug use disorder ${ }^{\mathrm{c}}$ & 1.8 & 6.6 & 19.1 & 10.0 \\
\hline
\end{tabular}

Continuous variables are reported as unlogged frequencies

${ }^{\text {a }}$ Past year

${ }^{\mathrm{b}}$ Change from emerging adulthood to young adulthood

${ }^{\mathrm{c}}$ Lifetime diagnosis

d Range: 0-365

e Range: $-365-235$

${ }^{\mathrm{f}}$ Range: $-365-365$

group membership $\left(\chi^{2}=12.28, d f=2 ; p<0.01\right)$. White men were over-represented in the non-violent group (67.2\% of White men vs. $49.8 \%$ of Black men) and Black men were over-represented in the persister group ( $8.2 \%$ of Black men vs. $4.0 \%$ of White men) and desister group (42.0\% of Black men vs. $28.6 \%$ of White men). (Note that there were two White men and eight Black men in the very late-onset group.) There were also group differences in incarceration $\left(\chi^{2}=75.06, d f=2, p<0.001\right)$ with only $4.1 \%$ of the non-violent group incarcerated between ages 26 and 36, compared to $25.6 \%$ of the desisters and $65.2 \%$ of the persisters. (Note that $40.0 \%$ of the late-onset group was incarcerated between ages 26 and 36.)

As shown in Table 3, there were no significant differences between non-violent men and the other two groups in the frequency of alcohol use or binge drinking in the past year. In contrast, desisters reported a significantly greater frequency of marijuana use, compared to non-violent men. From emerging to young adulthood, both persisters and desisters decreased their frequency of alcohol and marijuana use significantly more than the non-violent men. In Table 3, this is reflected by significant, albeit small, odds ratios. The small magnitude of these odds ratios is due to the nature of the change variables (difference in frequency). Persisters and desisters, compared to non-violent men, were significantly more likely to use hard drugs, to deal drugs, and to receive a lifetime alcohol use and hard drug use disorder diagnosis. In addition, compared to non-violent men, persisters were more likely to receive a lifetime diagnosis for a cannabis use disorder. 
There were no significant differences between persisters and desisters on any outcome except changes in alcohol and marijuana frequency. Persisters reduced their alcohol and marijuana frequency more than desisters from emerging to young adulthood.

\section{Discussion}

This study examined the associations between substance use and serious violent offending in young adulthood. We found that non-violent men differed from the persisters and/or desisters on every outcome except alcohol use frequency and binge drinking. There were no significant differences between persisters and desisters in any substance use variable except changes in substance use for which persisters decreased more than desisters.

Overall, our results indicate that more frequent drinking and binge drinking were not related to persistence of serious violent offending in young adulthood, which is consistent with what White et al. [56] found for emerging adulthood. White et al. [56] had expected that the lack of a relationship was due to the normative nature of heavy drinking during emerging adulthood and had hypothesized that there would be a relationship in young adulthood as the non-violent men matured out of heavy drinking. Although all three groups showed reductions in drinking frequency at age 36, persisters

Table 3 Multinomial regression analysis of substance use behaviors among violence groups

\begin{tabular}{llll}
\hline & $\begin{array}{l}\text { Desisters vs. } \\
\text { non-violent men }\end{array}$ & $\begin{array}{l}\text { Persisters vs. } \\
\text { non-violent men }\end{array}$ & $\begin{array}{l}\text { Persisters vs. } \\
\text { desisters }\end{array}$ \\
\hline $\begin{array}{l}\text { Continuous variables } \\
\text { Alcohol use frequency }{ }^{\mathrm{a}, \mathrm{b}}\end{array}$ & $0.958[0.848,1.082]$ & $0.779[0.604,1.005]$ & $0.814[0.635,1.043]$ \\
Binge drinking frequency $^{\mathrm{a}, \mathrm{b}}$ & $1.021[0.862,1.209]$ & $0.904[0.620,1.318]$ & $0.885[0.614,1.276]$ \\
Marijuana use frequency $^{\mathrm{a}, \mathrm{b}}$ & $1.202[1.082,1.335]^{*}$ & $1.191[0.953,1.489]$ & $0.991[0.800,1.228]$ \\
Change in alcohol use $^{\mathrm{c}}$ & $0.997[0.995,0.999]^{*}$ & $0.992[0.988,0.996]^{*}$ & $0.996[0.992,1.000]^{*}$ \\
Change in marijuana use & $0.997[0.995,0.999]^{*}$ & $0.992[0.995,0.999]^{*}$ & $0.995[0.992,0.999]^{*}$ \\
Categorical variables $^{\text {Any hard drug use }}{ }^{\mathrm{a}}$ & $4.554[1.994,10.403]^{*}$ & $8.425[2.151,33.005]^{*}$ & $1.850[0.540,6.335]$ \\
Drug dealing $^{\mathrm{a}}$ & $4.277[1.456,12.567]^{*}$ & $10.547[2.410,46.152]^{*}$ & $2.466[0.738,8.238]$ \\
Alcohol use disorder $^{\mathrm{d}}$ & $1.921[1.182,3.123]^{*}$ & $2.970[1.097,8.043]^{*}$ & $1.546[0.588,4.047]$ \\
Cannabis use disorder $^{\mathrm{d}}$ & $2.301[0.972,5.447]$ & $4.425[1.175,16.665]^{*}$ & $1.923[0.587,6.303]$ \\
Hard drug use disorder $^{\mathrm{d}}$ & $3.672[1.056,12.763]^{*}$ & $10.691[1.997,57.245]^{*}$ & $2.912[0.722,11.748]$ \\
\hline
\end{tabular}

Data are presented as odds ratios with $95 \%$ confidence intervals in brackets. All analyses controlled for race and incarceration. Each predictor was tested individually

$* p<0.05$

${ }^{\text {a }}$ Past year

${ }^{\mathrm{b}}$ Log transformed variables were used

${ }^{\mathrm{c}}$ Rounded to 3 decimal places but the full confidence interval does not include 1.00

${ }^{\mathrm{d}}$ Lifetime diagnosis 
and desisters, compared to non-violent men, reported significantly greater reductions and persisters reduced more than desisters. This finding is likely related to differences between the groups in peak alcohol use frequencies during emerging adulthood, with the persisters demonstrating the highest peaks and the non-violent group showing the lowest (not shown). The same interpretation holds for reductions in marijuana use.

The lack of a significant relationship between alcohol use and violence may be due to the use of a frequency rather than quantity measure. That is, heavy drinking and specifically intoxication may be more strongly related to violence than frequent use of low quantities of alcohol [29]. Nonetheless, frequency of binge drinking, which reflects higher quantities of drinking, was also not significantly related to violent offending. The non-significant findings may also be due to the fact that we measured drinking and binge drinking frequency over a full year rather than specifically in relation to the time of offending. Intoxication at the time of an offense might be a more critical factor for violent behavior [29]. In addition, in this study, we combined all types of serious violence, although heavy drinking may be related more strongly to some types than to others (e.g., assault vs. armed robbery) [16].

In contrast to the negative findings for alcohol, the findings for drug use were consistent in indicating a strong association of drug use behaviors with violent offending. Specifically, the use of hard drugs and drug dealing in young adulthood were linked to a history of serious violent offending as was having a lifetime diagnosis of a hard drug use disorder. Furthermore, a lifetime diagnosis of a cannabis use disorder was associated specifically with persistence of offending and frequent marijuana use was associated specifically with desistance. As has been suggested in other studies (e.g., [48]), violent offenders may become enmeshed in a culture of deviance, which supports a drug-using lifestyle. The fact that desisters also were more likely to use hard drugs, deal drugs, and use marijuana more frequently than non-violent men suggests that the former group had already become ensnared in a culture of deviance but were able to avoid committing a serious violent crime during the past 10 years.

In contrast to our findings, Laub and Sampson [27] found that alcohol abuse contributed to sustained patterns of violent offending and to episodic patterns of violent offending. They attributed this effect to the fact that heavy drinking interferes with good marriages and careers and also to the pharmacological effects of alcohol on aggressive behavior. On the other hand, Schroeder et al. [48] found that drug use, compared to alcohol use, was more strongly associated with persistent offending. They suggested that Laub and Sampson's [27] findings may be outdated due to the fact that their participants were predominately White and grew up in a different historical period when illicit drug use was less prevalent (i.e., Laub and Sampson's [27] participants were teenagers in the 1940s, whereas the PYS men were teenagers in the late 1980s and early 1990s).

Surprisingly, there were no differences between desisters and persisters in terms of any of the current substance use variables or lifetime substance use disorders. However, prevalence of hard drug use, dealing, and diagnoses were consistently but nonsignificantly higher in the persister, compared to desister, groups. The small number of persisters may have limited the power to find significant differences. It is also possible that the lack of significant differences between these groups was due to that fact that the desister group included those who stopped before emerging adulthood as well as those who stopped after. Thus, as suggested above, later desisters may already 
have become involved in deviant subcultures that reinforced their drug use and drug dealing.

Serious violent offenders may differ from other types of offenders in terms of individual factors, such as temperament and psychopathology [3, 31, 38, 49], or contextual factors, such as neighborhoods [10]. These factors, compared to substance use, might be more strongly related to persistence of serious violent offending and better able to distinguish serious violence persisters from desisters (see [34]). Nonetheless, using personal narratives, Laub and Sampson [27] found that violent offending is an intermittent behavior and may not be prospectively predictable over the life course. In fact, they discussed the dangers of taxonomies and argued that the longer the time frame studied, the more uncertain a taxonomy becomes. Furthermore, Laub and Sampson [27] suggested that, in addition to individual and environmental factors, social interactions and random chance events influence the life course of crime. Future research needs to consider individual and contextual factors when trying to discriminate persisters from desisters. Nevertheless, some studies suggest that it is quite difficult to accurately predict later violent behavior [20].

We found that most men who had committed a serious violent offense in adolescence and/or emerging adulthood did not commit a serious violent offense in young adulthood. Therefore, most of White et al.'s [56] desisters remained desisters, most lateonset and one-time offenders desisted, and most persisters became desisters. Furthermore, most non-violent men remained non-violent and only ten men became very lateonset violent offenders. This finding is consistent with a study on general offending by Farrington and colleagues [15], which demonstrated relatively strong stability in classes of offenders, especially beyond the early $30 \mathrm{~s}$, and with the age-crime curve in general [8].

In addition to the limitations discussed above regarding the alcohol use measures, there are other limitations that should be considered when evaluating our results. Official offending was based on convictions, similar to the White et al. [56] paper. However, extraneous factors (e.g., legal representation, plea bargaining) sometimes influence convictions [44]. We controlled for any incarceration during the 10-year period between emerging and young adulthood but not for the number of days incarcerated, which may have affected time at risk. Men reported on their violent offending over a 10-year period, which may have been affected by recall error; however, they only had to remember if they had committed any offense, not how many or when. A measure of lifetime diagnosis of substance use disorders was used rather than current diagnosis, which affects the temporal association with the violence group classification. The sample included only Black and White men from one geographic area in the United States. Thus, the generality of findings needs to be replicated with women, other ethnic/racial groups, and other geographical samples.

Despite these limitations, this study contributes to the literature on violent offending by being one of the only studies in the United States to empirically examine the association between alcohol and drug use and persistence of serious violent offending into the middle 30s. The results suggest that, beyond adolescence, illicit drug use, compared to alcohol use, may play a more important role in serious violent offending. The association may be reciprocal and may reflect involvement of violent offenders in a drug culture, which reinforces their offending rather drug use being a direct cause of violent behavior. Future research should consider both acute and chronic drug effects 
when studying violent offending. Furthermore, this study demonstrates the importance of longitudinal research for understanding criminal career patterns and the need for extended follow-ups beyond the 20 s for identifying persistence and desistance of serious violent offending (see also [27]).

Acknowledgments The writing of this paper was supported by grants from the National Institute on Drug Abuse (DA034608) and National Institute on Alcohol Abuse and Alcoholism (AA017473). The Pittsburgh Youth Study has also received funding from National Institute on Drug Abuse (DA011018), National Institute on Alcohol Abuse and Alcoholism (ARRA AA016798), National Institute of Mental Health (MH48890, MH50778, MH078039, MH056630), Pew Charitable Trusts, the Office of Juvenile Justice and Delinquency Prevention (96-MU-FX-0012), and the Pennsylvania Department of Health. Points of view, opinions, and content in this article are those of the authors and do not necessarily represent the official position or policies of the U.S. Department of Justice and National Institutes of Health. We thank Rebecca Stallings for help with the data set, Theresa Simpson for her help with preliminary analyses, and three anonymous reviewers for their suggestions.

Ethical Standards This study has been approved by the appropriate ethics committee and has therefore been performed in accordance with the ethical standards laid down in the 1964 Declaration of Helsinki and its later amendments. All participants gave their informed consent prior to their inclusion in the study (participants gave assent through age 17 and written consent thereafter; a primary caretaker gave written consent until the participants men provided their own written consent).

Conflict of Interest The authors report no conflict of interest.

\section{References}

1. American Psychiatric Association. (2000). Diagnostic and statistical manual of mental disorders (text revision) (4th ed.). Washington: American Psychiatric Association.

2. Bachman, J. G., O’Malley, P. M., Schulenberg, J. E., Johnston, L. D., Bryant, A. L., \& Merline, A. C. (1997). The decline of substance use in young adulthood: Changes in social activities, roles, and beliefs. Mahwah: Erlbaum.

3. Beaver, K. M., Schwartz, J. A., \& Gajos, J. M. (2015). A review of the genetic and gene-environment interplay contributors to antisocial phenotypes. In J. Morizot \& L. Kazemian (Eds.), The development of criminal and antisocial behavior (pp. 109-122). New York: Springer Press.

4. Bottoms, A., Shapland, J., Costello, A., Holmes, D., \& Muir, G. (2004). Towards desistance: theoretical underpinnings for an empirical study. The Howard Journal of Criminal Justice, 43(4), 368-389.

5. Bushway, S. D., Thornberry, T. P., \& Krohn, M. D. (2003). Desistance as a developmental process: a comparison of static and dynamic approaches. Journal of Quantitative Criminology, 19(2), 129-153.

6. Craig, J. M., Morris, R. G., Piquero, A. R., \& Farrington, D. P. (2015). Heavy drinking ensnares adolescents into crime in early adulthood. Journal of Criminal Justice, 43, 142-151.

7. De Li, S., Priu, H. D., \& MacKenzie, D. L. (2000). Drug involvement, lifestyles and criminal activities among probationers. Journal of Drug Issues, 30(3), 593-620.

8. De Lisi, M. (2015). Age-crime curve and criminal career patterns. In J. Morizot \& L. Kazemian (Eds.), The development of criminal and antisocial behavior: Theory, research and practical applications (pp. 51-63). New York: Springer Press.

9. Elliott, D. Z., Huizinga, D., \& Ageton, S. S. (1985). Explaining delinquency and drug use. Beverly Hills: Sage Publications.

10. Elliott, M. C., Dupéré, V., \& Leventhal, T. (2015). Neighborhood context and the development of criminal and antisocial behavior. In J. Morizot \& L. Kazemian (Eds.), The development of criminal and antisocial behavior (pp. 253-265). New York: Springer Press.

11. Ezell, M. E. (2007). The effect of criminal history variables on the process of desistance in adulthood among serious youthful offenders. Journal of Contemporary Criminal Justice, 23(1), $28-49$.

12. Fagan, J. (1990). Intoxication and aggression. In M. Tonry \& J. Q. Wilson (Eds.), Drugs and crime (pp. 241-320). Chicago: University of Chicago Press. 
13. Falk, Ö., Wallinius, M., Lundström, S., Frisell, T., Anckarsäter, H., \& Kerekes, N. (2014). The 1\% of the population accountable for $63 \%$ of all violent crime convictions. Social Psychiatry and Psychiatric Epidemiology, 49(4), 559-571.

14. Farrington, D. P., \& Hawkins, J. D. (1991). Predicting participation, early onset and later persistence in officially recorded offending. Criminal Behaviour and Mental Health, 1(1), 1-33.

15. Farrington, D. P., Piquero, A. R., \& Jennings, W. G. (2013). Offending from childhood to late middle age: recent results from the Cambridge Study in Delinquent Development. New York: Springer.

16. Felson, R. B., Burchfield, K. B., \& Teasdale, B. (2007). The impact of alcohol on different types of violent incidents. Criminal Justice and Behavior, 34(8), 1057-1068.

17. Giancola, P. R. (2002). Alcohol-related aggression during the college years: theories, risk factors, and policy implications. Journal of Studies on Alcohol, Supplement, 14 Mar, 129-139.

18. Goldstein, P. J. (1985). The drugs/violence nexus: a tripartite conceptual framework. Journal of Drug Issues, 15(4), 493-506.

19. Gottfredson, M., \& Hirschi, T. (1990). A general theory of crime. Stanford: University Press.

20. Hanson, H. R. (2009). The psychological assessment of risk for crime and violence. Canadian Psychology, 50, 172-182.

21. Helzer, J. E., \& Robins, L. N. (1988). The diagnostic interview schedule: its development, evolution, and use. Social Psychiatry and Psychiatric Epidemiology, 23(1), 6-16.

22. Hussong, A. M., Curran, P. J., Moffitt, T. E., Caspi, A., \& Carrig, M. M. (2004). Substance abuse hinders desistance in young adults' antisocial behavior. Development and Psychopathology, 16(4), 1029-1046.

23. Jessor, R., \& Jessor, S. (1977). Problem behavior and psychosocial development. A longitudinal study of youth. New York: Academic.

24. Kazemian, L. (2007). Desistance from crime theoretical, empirical, methodological, and policy considerations. Journal of Contemporary Criminal Justice, 23(1), 5-27.

25. Kazemian, L., Farrington, D. P., \& Le Blanc, M. (2009). Can we make accurate long-term predictions about patterns of de-escalation in offending behavior? Journal of Youth and Adolescence, 38(3), 384-400.

26. Labouvie, E. (1996). Maturing out of substance use: selection and self-correction. Journal of Drug Issues, 26(2), 457-476.

27. Laub, J. H., \& Sampson, R. J. (2003). Shared beginnings, divergent lives. Cambridge: Harvard University Press.

28. Le Blanc, M., \& Loeber, R. (1998). Developmental criminology upgraded. In M. Tonry \& N. Morris (Eds.), Crime and justice handbook (pp. 115-198). Chicago: University of Chicago Press.

29. Leonard, K. E. (2008). The role of drinking patterns and acute intoxication in violent interpersonal behaviors. In International Center for Alcohol Policies (Commissioner). Alcohol and violence: Exploring patterns and responses. Washington, DC: International Center for Alcohol Policies.

30. Loeber, R. (1988). Natural histories of conduct problems, delinquency, and associated substance use. In B. B. Lahey \& A. E. Kazdin (Eds.), Advances in clinical child psychology (Vol. 11, pp. 73-124). New York: Plenum.

31. Loeber, R., Byrd, A. L., \& Farrington, D. P. (2015). Why developmental criminology is still coming of age: the influence of biological factors on within-individual change. In J. Morizot \& L. Kazemian (Eds.), The development of criminal and antisocial behavior (pp. 65-73). New York: Springer Press.

32. Loeber, R., \& Farrington, D. P. (Eds.). (2012). From juvenile delinquency to adult crime: Criminal careers, justice policy, and prevention. Oxford: Oxford University Press.

33. Loeber, R., Farrington, D. P., Stouthamer-Loeber, M., \& White, H. R. (2008). Violence and serious theft: developmental course and origins from childhood to adulthood. New York: Routledge Press.

34. Loeber, R., Pardini, D., Homish, D. L., Wei, E. H., Crawford, A. M., Farrington, D. ... Rosenfeld, R. (2005). The prediction of violence and homicide in young men. Journal of Consulting and Clinical Psychology, 73(6), 1074-1068.

35. Masten, A. S., Faden, V. B., Zucker, R. A., \& Spear, L. P. (2008). Underage drinking: a developmental framework. Pediatrics, 121(Supplement 4), S235-S251.

36. Miczek, K. A., DeBold, J. F., Haney, M., Tidey, J., Vivian, J., \& Weerts, E. M. (1994). Alcohol, drugs of abuse, aggression, and violence. In A. J. Reiss \& J. A. Roth (Eds.), Understanding and preventing violence, 3 (pp. 377-468). Washington: National Academy Press.

37. Moffitt, T. E. (1993). Adolescence-limited and life-course-persistent antisocial behavior: a developmental taxonomy. Psychological Review, 100(4), 674-701.

38. Morizot, J. (2015). The contribution of temperament and personality traits to criminal and antisocial behavior development and desistance. In J. Morizot \& L. Kazemian (Eds.), The development of criminal and antisocial behavior: Theory, research and practical applications (pp. 137-165). New York: Springer Press. 
39. Morizot, J., \& Le Blanc, M. (2007). Behavioral, self, and social control predictors of desistance from crime a test of launch and contemporaneous effect models. Journal of Contemporary Criminal Justice, 23(1), 50-71.

40. NIAAA (2004). NIAAA council approves definition of binge drinking. NIAAA Newsletter, No. 3. Washington, DC: NIAAA.

41. Nilsson, A., Estrada, F., \& Backman, O. (2014). Offending, drug abuse and life chances-a longitudinal study of a Stockholm birth cohort. Journal of Scandinavian Studies in Criminology and Crime Prevention, 15(2), 128-142.

42. Nilsson, T., Wallinius, M., Gustavson, C., Anckarsater, H., \& Kerekes, N. (2011). Violent recidivism: a long-time follow-up study of mentally disordered offenders. PLoS ONE, 6(10), Art e25768.

43. Osgood, D. W., Johnston, L. D., O’Malley, P. M., \& Bachman, J. G. (1988). The generality of deviance in late adolescence and early adulthood. American Sociological Review, 53, 81-93.

44. Pardini, D, Bechtold, J., Loeber, R., \& White, H. R. (2015). Developmental trajectories of marijuana use among men: examining linkages with criminal offending and psychopathic features into the mid-30s. Journal of Research in Crime and Delinquency.

45. Piquero, A. R., Blumstein, A., Brame, R., Haapanen, R., Mulvey, E. P., \& Nagin, D. S. (2001). Assessing the impact of exposure time and incapacitation on longitudinal trajectories of criminal offending. Journal of Adolescent Research, 16, 54-74.

46. Reyes, H. L. M., Foshee, V. A., Bauer, D. J., \& Ennett, S. T. (2011). The role of heavy alcohol use in the developmental process of desistance in dating aggression during adolescence. Journal of Abnormal Child Psychology, 39(2), 239-250.

47. SAS Institute (2002-2008). SAS for Windows (Version 9) [Computer program]. Cary, NC: Author.

48. Schroeder, R., Giordano, P., \& Cernkovich, S. (2007). Drug use and desistance processes. Criminology, 45, 191-222.

49. Séguin, J. R., Pinsonneault, M., \& Parent, S. (2015). Executive function and intelligence in the development of antisocial behavior. In J. Morizot \& L. Kazemian (Eds.), The development of criminal and antisocial behavior (pp. 123-135). New York: Springer Press.

50. Stoolmiller, M., \& Blechman, E. A. (2005). Substance abuse is a robust predictor of adolescent recidivism. Criminal Justice and Behavior, 32, 302-328.

51. Stouthamer-Loeber, M., Wei, E., Loeber, R., \& Masten, A. S. (2004). Desistance from persistent serious delinquency in the transition to adulthood. Development and Psychopathology, 16(04), 897-918.

52. White, H. R. (2014). Substance use and crime. In K. J. Sher (Ed.), Psychology and substance abuse. Oxford: Oxford University Press.

\section{Online first.}

53. White, H. R. (2015). Developmental approaches to understanding the substance use-crime connection. In J. Morizot \& L. Kazemian (Eds.), The development of criminal and antisocial behavior: Theory, research and practical applications (pp. 379-397). New York: Springer Press.

54. White, H. R. Bechtold, J., \& Pardini, D. (2015, May). The effects of marijuana use in adolescence and emerging adulthood on adult functioning: A developmental perspective. Poster presented at the Society for Prevention Research annual meeting. Washington, DC.

55. White, H. R., \& Labouvie, E. W. (1994). Generality versus specificity of problem behavior. Psychological and functioning differences. Journal of Drug Issues, 24, 55-74.

56. White, H. R., Mun, E.-Y., Lee, C., \& Loeber, R. (2012). Developmental patterns of alcohol use in relation to persistence and desistance of violent offending among African American and Caucasian young men. Criminology, 50, 391-426. 